\section{Localized Corrosion of Chromium Coated Steel}

$$
\begin{gathered}
\text { X. Zhang }{ }^{(1,2)} \text {, P. Beentjes } \\
\text { J.H.W. de Wit. }{ }^{(1,2)} \\
{ }^{(1)} \text { Netherlands Institute for Metals Research (NIMR) } \\
\text { Mekelweg 2, } 2628 \text { CD Delft, The Netherlands }
\end{gathered}
$$

${ }^{(2)}$ Department of Materials Science and Engineering, Delft University of Technology, Mekelweg 2, 2628 CD Delft, The Netherlands

${ }^{(3)}$ Corus Research, Development and Technology, P.O. Box 10.000, 1970 CA IJmuiden, The Netherlands

\section{Introduction}

Electrolytically chromium coated steel is widely used in packaging industry $[1,2]$. The chromium coating can protect carbon steel from corrosion. However, the defects in the $\mathrm{Cr}$ coating or the coverage of the steel surface may affect the protection. Scanning vibrating electrode technique (SVET) can be used to locate anodic and cathodic sites in coated steel using a current density mapping method [3].

In this paper, we report on the studies of the local corrosion behaviour of chromium-coated ultra low carbon steel in $\mathrm{NaCl}$ solution using polarization, electrochemical impedance spectroscopy (EIS) and SVET.

\section{Experimental}

The substrate is ultra low carbon steel sheet $(\sim 0.2 \mathrm{~mm}$ thick). Chromium was electroplated on the steel in a chromate bath. The $\mathrm{Cr}$ coatings are in different thickness: one is $0.01 \mu \mathrm{m}$ and the other is $1.06 \mu \mathrm{m}$ thick. The morphology of coated samples was analyzed using SEM and AFM. The corrosion resistance of these specimens in 3.5\% $\mathrm{NaCl}$ solution was investigated using d.c. polarization and a.c. impedance measurements. The local anodic and cathodic current densities were scanned using SVET in $0.001 \mathrm{M} \mathrm{NaCl}$ solution.

\section{Results and discussions}

Polarization measurements show that the corrosion potentials of the specimens move in the positive direction with increase of the thickness of the $\mathrm{Cr}$ coating (see Fig. 1). The corrosion current density of the Cr-coated sheets depends also on the thickness of the coating. The specimens with a thin chromium coating $(0.01 \mu \mathrm{m}$ thick) showed a larger corrosion current density than the specimens with a thick coating $(1.06 \mu \mathrm{m})$. It indicates that a thin chromium layer did not cover the whole steel surface. The EIS results are in agreement with these results. The SVET measurements show that three anodic sites in a small area (about $0.5 \times 0.7 \mathrm{~mm}$ ) have been detected. One pit initiated first and the peak of the anodic current density increased with time. After some time this current density peak became shorter and other two pits started (see Fig. 2). The surrounding area was cathodic. For the specimens with a thick chromium layer $(1.06 \mu \mathrm{m})$ no significant defect was observed.

\section{Conclusions}

The chromium coating can improve the corrosion resistance of the ultra low carbon steel. The Cr-coated carbon steel shows a localized corrosion in $\mathrm{NaCl}$ solution. The corrosion resistance depends on the thickness of the $\mathrm{Cr}$ coating. Pitting does not initiate at all defects at the same time. The pitting process is unstable. After a pit is covered by corrosion product a new anodic site may start to corrode.

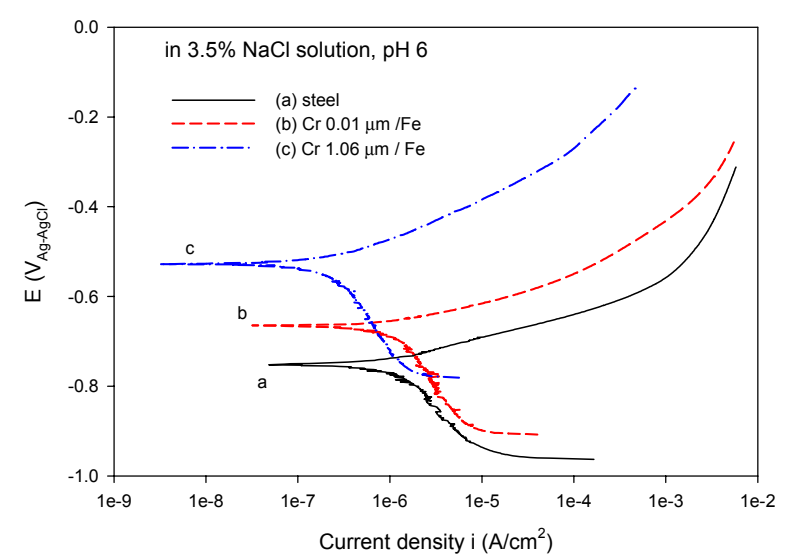

Fig. 1 Polarization curves for low carbon steel with and without $\mathrm{Cr}$ coating in $3.5 \% \mathrm{NaCl}$ solution.

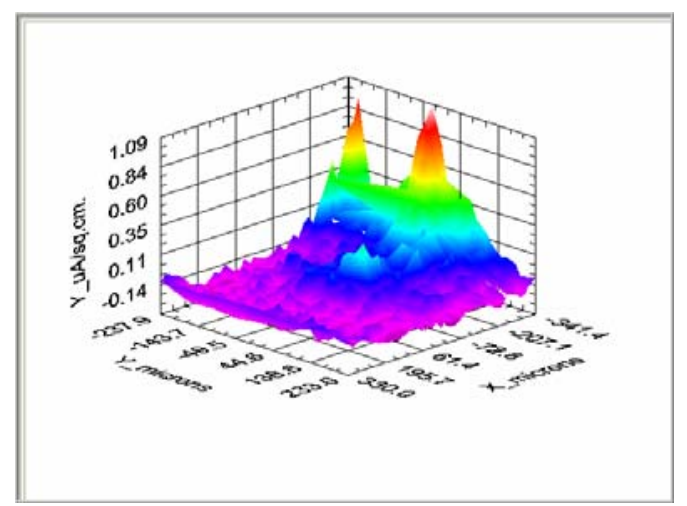

Fig. 2 (a) Current density map for the Cr-coated steel with a $0.01 \mu \mathrm{m} \mathrm{Cr}$ layer, obtained in $0.001 \mathrm{M} \mathrm{NaCl}$ solution for 1.5 h.

\section{References}

[1] P. Beentjes, Durability of polymer coated steel in diluted acetic acid environment, PhD Thesis, TU Delft, 2004.

[2] B. Boelen, H. den Hartog, and H. van der Weijde, Progress in Organic Coatings, 2004, 50, 40.

[3] H. S. Isaacs, A. J. Aldykiewicz, D. Thierry, and T. C. Simpson, Corrosion, 1996, 52, 163. 